\title{
DEVELOPMENT OF NOVEL ALGORITHMS AND ARCHITECTURE FOR A ROBOT BASED AGRICULTURAL IMPLEMENT
}

\author{
C. S. Mala*, S. Ramachandran\# \\ * Jawaharlal Nehru Technological University, Hyderabad \\ csmala63@yahoo.co.in \\ \# SJB Institute of Technology, Bangalore \\ ramachandr@gmail.com
}

\section{ABSTRACT}

This paper presents novel algorithms and architecture for a Robot based agricultural implement. The application is for tilling the agricultural field. The hardware consists of a platform with four wheels and a mechanism to facilitate the forward, reverse and lateral movement of the wheels. The platform also houses a turn table, a lift and a plough. Various user defined inputs may be programmed such as length and breadth of the field, spacing between two till lines and depth of tilling. Thereafter, the entire tilling operation of the field is automated. The Robot based vehicle begins the operation from the top left corner and moves towards right tilling the field as it moves forward. Once the required length of field is reached, the vehicle halts and moves to the next row for a specified spacing between tilled rows. The movement from one row to another is in a lateral fashion by rotating the Robotic vehicle wheels by 90 degrees. No tilling is carried out till the next row is reached. The tilling operation is resumed by rotating the plough by 180 degrees and moving the vehicle in the reverse direction. This process continues till the end of the field, covering the entire breadth and maintaining the desired spacing and depth. This automated tilling requires the development of novel algorithms and an optimized architecture, which is presented in this paper. The system is user friendly and upgradable. The entire system has been realized using Verilog and is RTL compliant. The design is both platform and technology independent. The design has been simulated using ModelSim.

\section{Keywords}

Customized IP Core; Robot; Agricultural Implement; Driverless Vehicle; Novel Algorithm; and Architecture.

\section{Council for Innovative Research}

Peer Review Research Publishing System

Journal: INTERNATIONAL JOURNAL OF COMPUTERS \& TECHNOLOGY

Vol 10, No 5

editor@cirworld.com

www.cirworld.com, member.cirworld.com 


\section{INTRODUCTION}

Hitherto agricultural operations were either bullock drawn or tractor driven. Automation was not introduced probably since farm lands were small, and mechanization equipments were expensive and hence not affordable by poor farmers. In order to automate agricultural practices and make technology affordable and available for large as well as small lands, many attempts have been made.

Choatpong Kanjanaphachoat, et. al [1] have addressed the improvement of an orchard Robotic Vehicle with respect to its the multi-path error in positioning systems. In their navigation system, they have coupled a differential global positioning system and double electric compass to estimate the position of the orchard vehicle in real time. Emphasis has been laid more on positioning the Robot ic Vehicle for application in an orchard.

T. Oksanen and A. Visala [2] have developed algorithms for a non rectangular field. They have presented two algorithms to solve the path planning problem for agricultural machines. The first being trapezoidal split, merges and search. This algorithm takes care of obstacle avoidance. The algorithm is suited to any kind of vehicle, with a few parameters, like working width and vehicle turning time. The second algorithm they have used is based on the bottom-to-top approach. It solves the problem recursively and it is designed for real-time usage. However, the emphasis in their paper has been more on path planning algorithms for an agricultural machine rather than its usage in agricultural practices from tilling to harvest.

The recent advances in agricultural Robotics are due to perception, manipulation and autonomous vehicles. John Billingsley [3] is of the opinion that the goal of agricultural robotics is not only to apply robotics technologies in the field of agriculture but also to address challenges posed in developing new techniques and systems. Sensors are basically employed for perception. His paper states that manipulation is limited to simple tasks like spraying, where accuracy is not required. Driverless vehicles are used in a coordinated and robust manner to operate vast farm lands. The author does not deal specifically with any application in agriculture.

Xu Jin, et. al [4] have used embedded system approach to develop an intelligent car. The authors have developed a chip based on ARM9 for a new smart car system. GPS and GPRS are used to introduce intelligence into the smart car. But this vehicle has not been used for farming or agricultural purposes.

Freitas G, et. al [5] have dealt with sensors on Robots for navigation in a driverless vehicle in fruit orchards. These vehicles navigate between rows carrying people. The challenge here is to adjust the speed on detecting people and bins in between the rows. In order to reduce the cost of the system, sensors already mounted on Robots are being used along with a laser scanner and a measurement unit. Wheel encoders have also been used in the feedback path to control the speed of the vehicle. The system cannot detect objects if they are covered by grass, and if they are less than $15 \mathrm{cms}$ in height.

Fang $\mathrm{H}$, et. al [6] have, in particularl, dealt with sliding effects in auto farming vehicles. They have addressed the problem by constructing a vehicle using kinematics. An adaptive controller has been designed to take care of the sliding effect in farm vehicles. To make the system more robust, a Variable Structure Controller or projection mapping has been integrated into adaptive controllers. They have achieved high accuracy in following the path.

Han, Y. H., Wang, Y. M. and Kang, F. [8] have introduced image processing in agriculture vehicle navigation. The image processing techniques were used to get information on the rows of crops. The broken ridges, weeds and other abnormalities were being addressed. Wavelet transformation techniques were used and the entire program was written in Matlab.

Hassan, M. H. and Rosati, M. [7] have developed Automated guided vehicles. These vehicles were used for material handling and transport. It was developed using a microcontroller and a sonar system. The farm applications were not taken into consideration.

Nielsen, K. M., et. al [9] have developed an autonomous vehicle for weed mapping in agriculture. They have used control system in three layers. The first layer controls steering of the vehicle. The second layer coordinates the wheel movement, while the third layer controls the execution and perception. The last layer takes care of planning and reasoning. They tested the path following the property of the vehicle and also its position accuracy. A new vehicle is being constructed using these test results. 
Oksanen, T., Linja, M. and Visala [10] A. have dealt with accurate positioning for agricultural vehicles. They have presented positioning of a tractor using GPS receiver. The positioning has been improved by inertial navigation and techniques of odometry. Advanced filters like Kalman filter have been used for sensor fusion. But they do not speak about vehicle automation for agricultural purposes.

Cariou, C. et. al [11] have dealt with path generation and motion control problems for a driverless farm vehicle. To guide the vehicle accurately, they have presented steering and speed control algorithms. Tests were carried out with an experimental mobile Robot. At the end of each row, the vehicle automatically turns to the next row. But the movement of the vehicle to the next row is not lateral.

R. V. Siva Reddy, et. al [12] have developed IP Core in Verilog for 8085 Microprocessor and have used the core for Electrostatic Precipitator processor to achieve significant speed of operation compared to 8085 based systems. It is used presently in the thermal power plants.

B. B. V. L. Deepak and Dayal Parhi [13] have developed a driverless mobile robot for path generation within its work space. The Robot has been taught to search for targets. They have introduced an adaptive learning-based motion planner using adaptive immune based path planner. The concentration of the paper is on teaching the autonomous mobile robot to plan the path.

The proposed paper presents the implementation of a Robot based vehicle control system using the IP core developed earlier by the present authors $[14,15]$ for tilling operation of a farm. We propose here the design of a system for Robot based agricultural implement such as a plough that would automate tilling operations and reduce time, labour and cost. We have achieved it through customized Intellectual Property (IP) Core, which may be implemented on an FPGA or as an ASIC.

This paper is organized as follows. Section 2 presents the basic architecture of a Robot based system for automating ploughing operations. Section 3 presents the overview of the system. Section 4 presents the development of Flow charts for the Robot control. Section 5 presents the Simulation Results and the last section presents the conclusions derived as well as work for future enhancements

\section{ARCHITECTURE OF THE PROPOSED ROBOT BASED AGRICULTURAL IMPLEMENT SYSTEM}

This work proposes the development of an automated agricultural implement system with a view to utilize it for agricultural practice such as tilling the field. The basic architecture of the proposed driverless Robotic vehicle system is presented in Figure 1. It comprises the following blocks:

1. Controller

2. Turn Table

3. Lift

4. Plough

5. Wheels and

6. Buzzer

Controller: It is the heart of the system for control and coordination of all the functions of the system. It controls the movement of plough, lift, turn table and wheels of the Robotic vehicle, etc. The controller takes in various user defined inputs and sends out appropriate signals at the right time for the operation of the Robotic vehicle in tilling the farm land. Spartan 3 Xilinx FPGA is proposed to be used for the Controller for our application.

Turn Table: The turn table is housed on the Robotic vehicle. It facilitates the agricultural tool to be always at the rear end of the vehicle during tilling operation. This enables the tilling operation in the forward as well in the reverse direction. As shown in Figure 1, the output port P3.0 is connected to the servo motor which controls the direction of the turn table. A pulse of $20 \mathrm{~ms}$ applied on P3.0 rotates the turntable from its initial position to the left of the vehicle to enable the tilling operation in the forward direction. Similarly a pulse of $10 \mathrm{~ms}$ on this pin rotates the turn table to the right of the vehicle to enable the tilling operation in the reverse direction.

Lift: Lift is connected to the shaft of the turn table with an L shaped bent rod. To the end of the rod is connected a servomotor which controls the lowering of the lift as shown in the figure. Plough connection is made at the end of the rod connected to the lift. Port P3.1 is connected to the servomotor. A pulse of $10 \mathrm{~ms}$ on this pin lowers the Lift from its initial position. The lift enables the plough to touch the surface of the ground. Once the plough reaches the ground then other adjustments are made to facilitate the tilling to the required depth. The Lift raises the plough above the ground surface when the vehicle has to make a lateral shift to the next line on completing the tilling of a row. This ensures that no tilling is carried out till the plough reaches the next row. During the vehicle's movement forward or reverse, and whenever any obstacle is detected, then the vehicle detours to avoid collision. During such a detour, the lift facilitates the raising of the plough above the ground so that the land remains untilled till it resumes the normal tilling line.

Plough: Plough is connected to the end of the lift and driven through a stepper motor which facilitates the plough to move to the depth specified. The rotary movement of the stepper motor is linearized piece-wise. 
Wheels: The Robotic vehicle moves on four wheels. They are positioned straight to facilitate the vehicle to move in the forward direction as well as in the reverse direction. Directions of vehicle motion such as forward, reverse, etc. are applied to Port P0 as indicated in Table 2, details of which are presented in Section 4. For the lateral movement of the vehicle, the wheels are rotated by 90 degrees by sending appropriate signals to the ports P1 and P2.

Sound Alarm: As shown in Figure 1, an alarm signal is sent out when the tilling operation of the entire field is completed or when errors are encountered.

\section{OVERVIEW OF THE PROPOSED ROBOTIC SYSTEM}

In order to commence the tilling operation in a field, the Agricultural Robotic Vehicle is placed at the left corner of the field, being its initial position. The turn table is in neutral position, the lift is in up position and the plough is above the ground and the wheels are at rest. Figure $2 \mathrm{a}$ shows the turn table of the vehicle moved to the left side and the lift and plough still in up position. Thereafter, the lift is lowered to place the plough on the surface, ready to till the field. Once the initial conditions are satisfied, the vehicle moves forward and traverses the length as set earlier. The vehicle halts after tilling a length. Thereafter the lift and the plough are lifted up and the turntable is brought to its initial condition since the servo motor used for this movement requires this feature for its correct operation. The wheels of the vehicle turn right by 90 degrees to facilitate the lateral movement to the next row. Once the vehicle reaches next row to be tilled, it halts. Then the wheels rotate by 90 degrees to facilitate reverse movement of the vehicle.

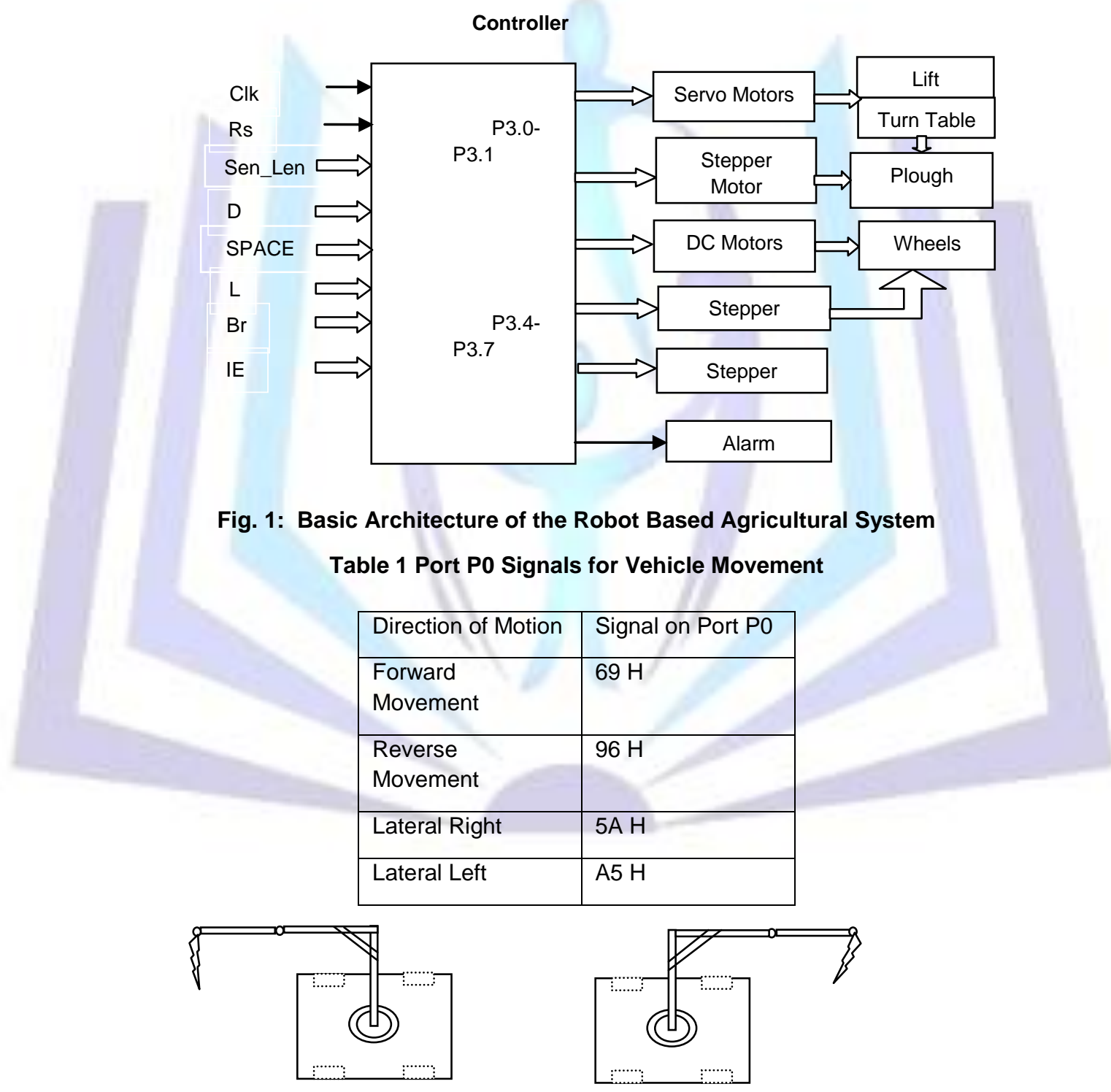

Fig. 2: Positioning of Turn Table of Robotic Vehicle for Tilling Operation

a Left for Forward Movement from initial position b Right for Reverse Movement 
The turn table then turns to the right side of the vehicle and again the lift and the plough are lowered to facilitate the reverse movement to till the ground. This is shown in Figure $2 \mathrm{~b}$. The turn table enables the plough and the lift arrangement to be always at the rear end of the vehicle.

\section{DEVELOPMENT OF FLOW CHARTS}

The flow charts for the entire operation of tilling the field by Robotic vehicle are presented in this section. The tilling operation is carried out in the following sequence:

\section{Forward Movement \\ 2. Lateral Movement and \\ 3. Reverse Movement.}

During the Forward or Reverse movement, if there is any obstacle detected, it is taken care of by an appropriate Interrupt Service Routine.

Forward Movement of the Vehicle:

The vehicle is placed on the top left corner of the field, which is the initial condition in the design. The entire sequence of steps for forward movement of the Robot based agricultural implement system is presented in Figure 3 . The initial condition ensures that the turn table is in neutral position, lift and plough in the up positions and the wheels stationary. The tilling parameters such as Length $(\mathrm{L})$, Breadth $(\mathrm{Br})$ of the field, spacing between till lines (SPACE), and the Depth of the ground to be tilled (D), are input. These parameters are dependent on the crop to be cultivated and hence they are User Programmable. The turn table is rotated towards the left of the vehicle and the Lift is lowered and the plough is adjusted for the required depth. The vehicle is now ready for the forward movement. In the next step, an appropriate signal is sent out to move the vehicle through the ports. The vehicle starts moving in the forward direction. If any obstacle is detected in front, then the IE.0 flag is set and the controller services the Interrupt Service Routine (ISR). If there is no obstacle in front, then it proceeds in the forward direction and checks if the vehicle has completed the length specified. If not, the vehicle continues to move in the forward direction. The vehicle stops if the specified length is completed. In the next step, the vehicle is moved laterally to the next row. The plough is lifted up, the lift and the turn table moves to neutral position once again.

\section{Lateral Movement:}

The wheels turn by 90 degrees to facilitate lateral movement. Appropriate signals are issued to the wheels through the ports to move the vehicle laterally to the next row. The vehicle movement is checked to see that it covers exactly the spacing distance between the till lines. Then the vehicle halts. The Breadth counter is decremented by one to indicate that tilling operation of one row is completed. Then the arrangement for backward movement of the vehicle is facilitated. The turn table is rotated to right side of the vehicle, the lift is lowered and specified depth is adjusted for the plough.

Reverse Movement of the Vehicle:

The sequence of operations for reverse movement of the Robot is presented in Figure 4 . Adjustments in the wheel, plough, lift and turn table for the reverse movement are made. In the next state, the appropriate signal is sent out to move the vehicle in reverse direction through the ports. The vehicle starts moving in the reverse direction. Obstacle detection and collision avoidance is taken care of as in forward movement. The vehicle movement is maintained till the completion of the length specified. Thereafter, the vehicle is set for the lateral movement to the next row. Plough is lifted up; the lift and the turn table moves to neutral position, after which the vehicle makes a lateral movement to the next row and decrements the breadth counter.

The forward and reverse movements are repeated till the entire breadth of the field is tilled completely.

\section{Obstacle Detection and Collision Avoidance:}

Figure 5 presents the detouring of the vehicle whenever any obstacle is encountered on its path. If any object is detected by the front sensors, then the vehicle halts immediately. The plough and the turn table are lifted up and the wheels turn right by 90 degrees and the vehicle makes a lateral movement. It continues in the lateral direction until the front sensor signals finds no obstacle in the front. Then the wheels turn again left by 90 degrees facilitating forward movement. The vehicle moves in the forward direction and checks for obstacles in the left direction using sensors fit to the left side of the vehicle. When the vehicle steers clear of the obstacle, it halts and then turns the wheels by 90 degrees and moves laterally up by the same distance that it has travelled downwards laterally. Thereafter, it lowers the plough and the lift and continues to till the ground in the forward direction till the specified length is reached. The same process is continued during any obstacle detection in the reverse direction. The point to be noted here is that during the forward movement of the vehicle, if any obstacle is detected by front sensor, the vehicle moves towards its right for detour. During the detour, the vehicle does not till the field and restarts tilling operation after it gets back to the forward line that needs to be tilled. The path taken by the Robotic vehicle is presented in detail in Figure 6 . The continuous lines indicate the tilled path. The dotted lines in Figure 6a-6c indicate untilled lines. Thereby, when the vehicle moves in the reverse direction, the spacing between the till lines is maintained and also avoids the vehicle falling into the till lines. During the reverse movement of the vehicle, the obstacle is detected by the rear sensors and upon detecting an object in its path, the vehicle now moves towards its left laterally and detours around the obstacle without tilling the field until it resumes the till lines in the reverse 
movement. In tilling the entire field, care is taken to see that the till line spacing is not disturbed and the vehicle at no point of time falls into the tilled lines
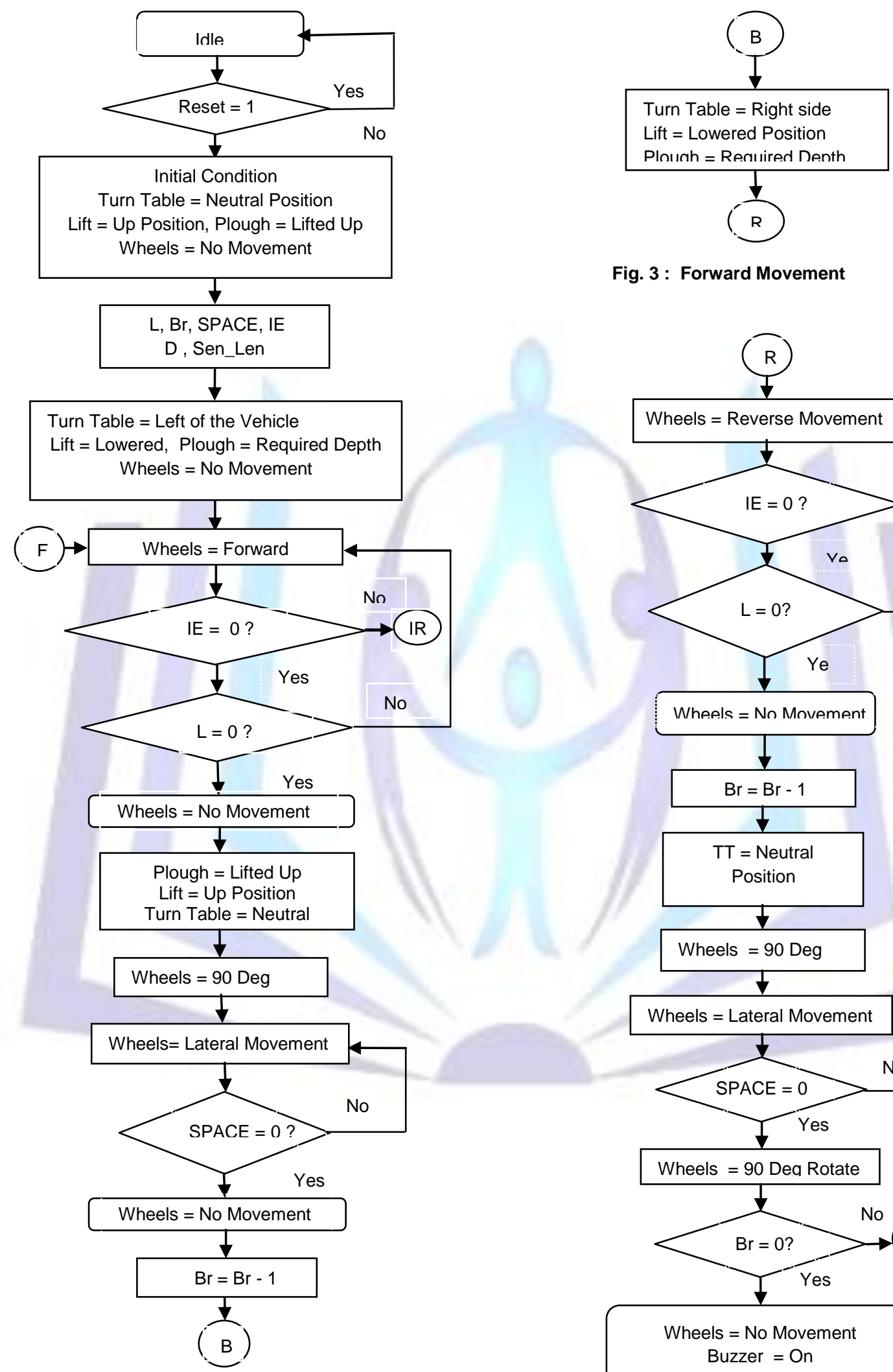

Fig. 3 : Forward Movement

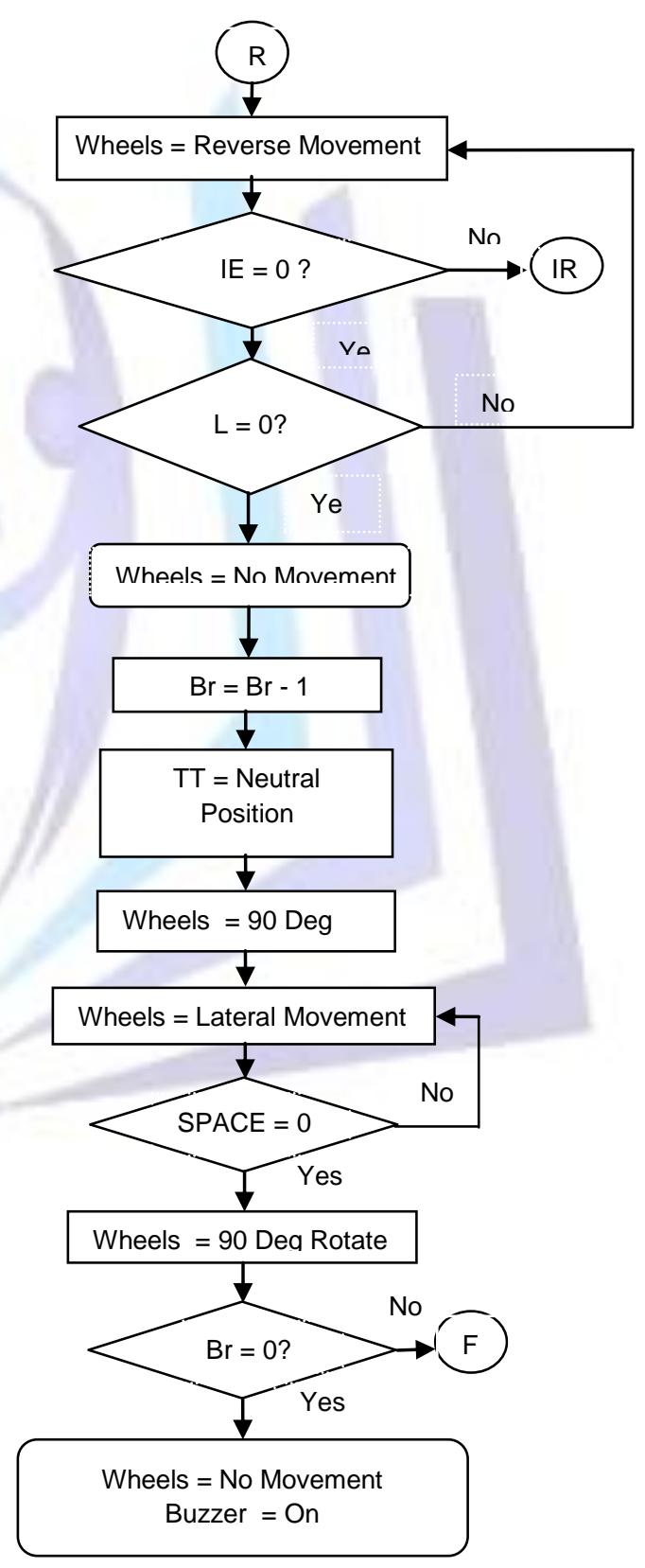

Fig. 4 : Reverse Movement 

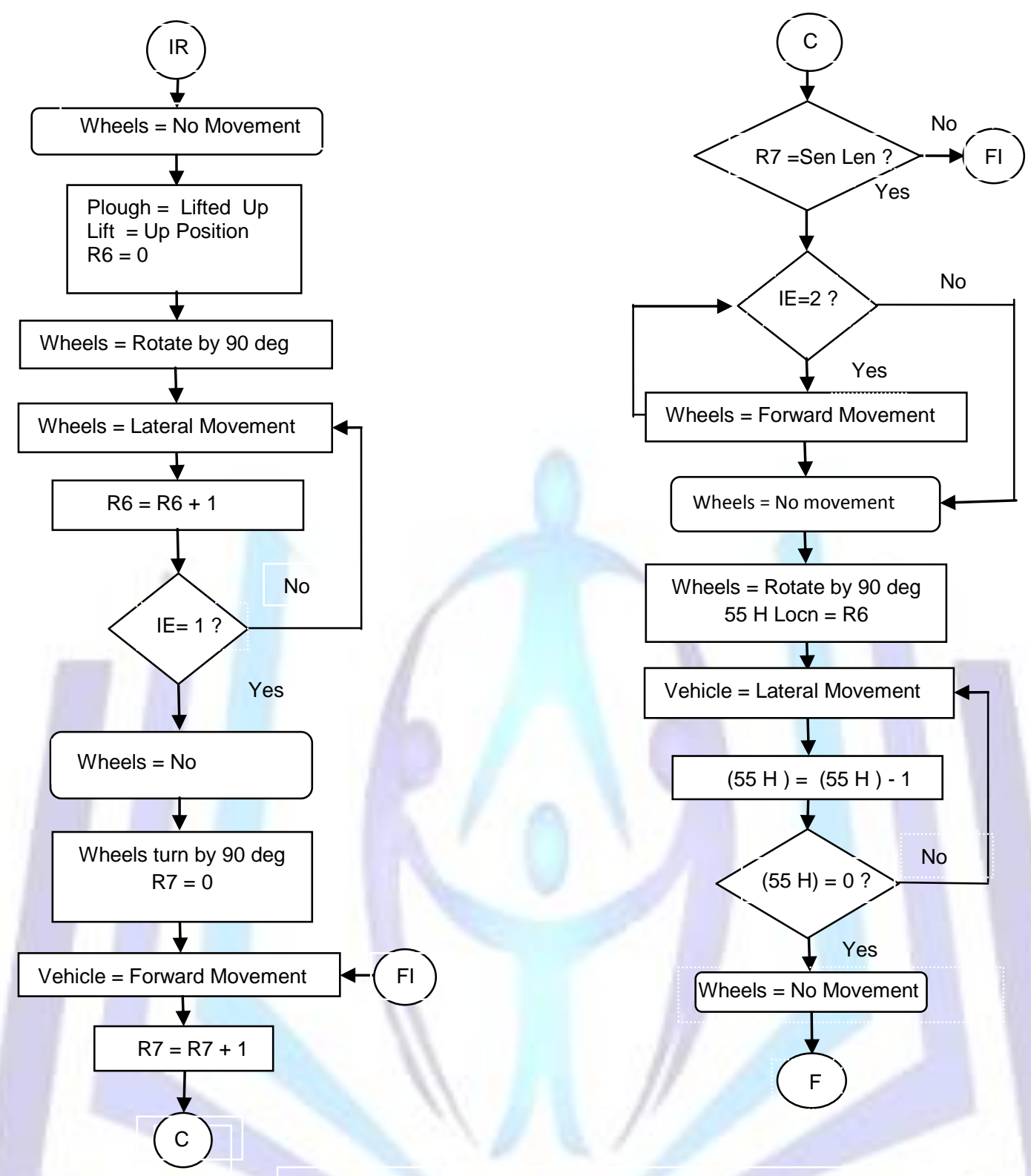

Fig. 5 : Obstacle Detection and Collision
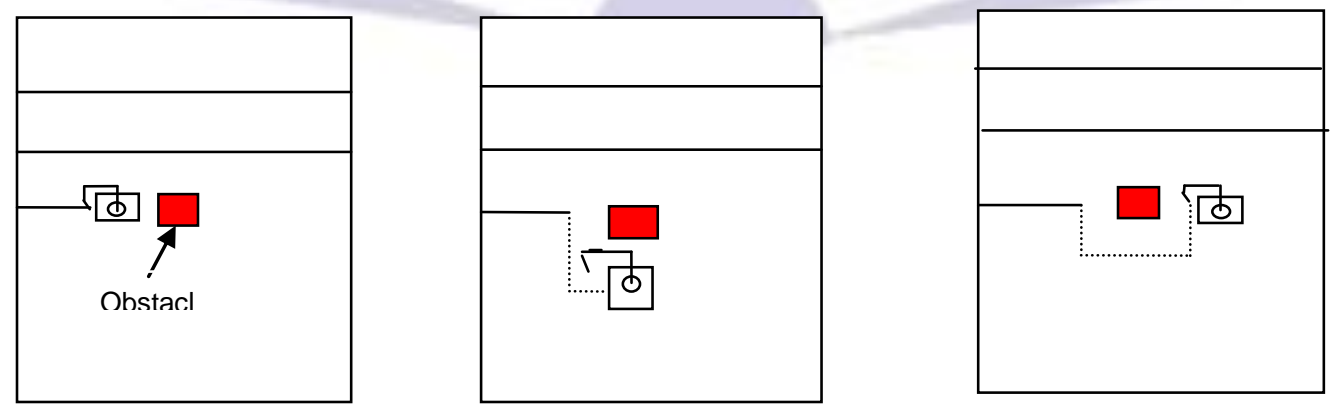

Fig. 6 : Path taken by the Robotic Vehicle on Obstacle Detection

a Obstacle Detected

b Vehicle Detour

c Forward Movement Resumed 


\section{SIMULATION RESULTS}

The simulation results of the Robotic Agricultural Implement are presented in this section. ModelSim simulator has been used to simulate the design of the entire system. The system has several inputs and outputs as presented in Table. 1. The first signal is the system "clk" operating at $50 \mathrm{MHz}$ frequency. The system reset signal is active high as shown in Figure 7. When the system reset signal is withdrawn, the user specified inputs such as $\mathrm{L}, \mathrm{Br}, \mathrm{SPACE}$, D are entered. The controller can take 255 meters as the maximum length of a field. For ease of simulation, the length is taken as 9 meters and the breadth as 5 meters. Spacing between two till lines is taken as 1 metre. The 'Sen_Len' is also input. It is the distance of the sensor to the obstacle and it is dependent on the sensor used. 'Sen_Len' taken is as 1 metre. Spacing between till lines is also taken as 1 meter. The depth of tilling " $D$ " is taken as 1 to get 6 inches depth. IE is the interrupt generated on detecting obstacles in front, back, left and right of the vehicle. The outputs are available at the Ports P0 to P3. Port P0 facilitates the forward, reverse and lateral movement of the vehicle. This is achieved by sending appropriate signals on Port P0. Port P1 and P2 facilitate turning of the wheels by 90 degrees for lateral movement. Port P3 upper nibble is used for depth control, P3.0 controls the rotation of the turn table, and P3.1 controls the movement of the lift. Port P3.2 indicates the completion of tilling operation. These input and output signals are presented in Figure 7.

Forward Movement: The forward movement of the Robotic Vehicle takes place only when appropriate signals are given to the wheels of the vehicle. For forward movement, the front left wheel and the rear left wheel should be moving in anticlockwise direction and at the same time front right wheel and rear right wheel should move in the clock wise direction. These wheels are connected to the port pins of P0. For the forward movement, the port P0 should have the combination of 01101001 in binary or $69 \mathrm{H}$. The Op code to output $69 \mathrm{H}$ on port P0 is $62 \mathrm{H}$. The Length counter (Lcount) keeps decrementing as the vehicle moves forward. Breadth counter (Bcount) remains the same until the completion of one full length. Stepper motors are connected to output ports P1 and P2 and is initialized to $00 \mathrm{H}$ indicating that the stepper motors are in initial condition when the vehicle moves in the forward direction. The movement of the vehicle can take place only when the controller is not reset. The reset is active high for this controller. This is presented in the waveform in Figure 8.

Reverse Movement: The Reverse movement of the Robotic Vehicle takes place only when the front and rear left wheels move in clockwise direction and at the same time front and rear right wheels move in the anti clock wise direction. For this movement, the port P0 has the combination of 10010110 in binary or $96 \mathrm{H}$. On completion of one full length, the breadth counter decrements by one before beginning the tilling operation in the reverse direction. 'Lcount' starts decrementing from 9. This waveform is presented in Figure 9a. Figure $9 \mathrm{~b}$ also presents the decrementing of 'Lcount' when breadth counter is 2 .

Lateral Right Movement: After completing the tilling of the length in the forward direction from left to right, the vehicle halts and then takes a lateral right movement to pass to the next row for further tilling. The wheels are turned by 90 degrees before the wheels make lateral movement. Turning of the wheels by 90 degrees is facilitated by stepper motor connected to ports $\mathrm{P} 1$ and $\mathrm{P} 2$. $\mathrm{P} 1$ and $\mathrm{P} 2$ are set to $11 \mathrm{H}$ and $88 \mathrm{H}$ respectively. This waveform is presented in Figure 10 . The lateral right movement of the Vehicle is made by energizing the four wheels appropriately. For the lateral right movement, the port $\mathrm{PO}$ is set to $5 \mathrm{~A} \mathrm{H}$.

Lateral movement: To turn the wheels by 90 degrees, the stepper motor rotates by 90 degrees. Each rotation of the stepper motor gives a 1.8 degree shift and to achieve 90 degrees rotation, the motor has to be stepped 50 times. For single coil excitation of the stepper motor, the pattern $88 \mathrm{H}$ is given to the windings. It is left shifted four times and the pattern $44 \mathrm{H}, 22 \mathrm{H}$ and $11 \mathrm{H}$ are passed on to the wheels of the stepper motor continuously to get 90 degrees rotation of the wheels. This pattern is output on ports $\mathrm{P} 1$ and $\mathrm{P} 2$ and is presented in Figure 11.

Collision Avoidance: Whenever an obstacle is encountered in the forward direction, then the front sensor generates an interrupt by making IE register equal to 1 and services the Interrupt Service Routine, which commences from address 1000. Program Counter gets loaded with the address 1000 after saving the return address on stack and the control transfers to address location 1000. This transfer is presented in Figure 12. IE register becomes 1 when front sensor detects an obstacle in front of it. If there is an obstacle to the left side of the vehicle it generates an interrupt making IE register equal to 2 and the program control is changed to location 1100. This is presented in Figure 13. Similarly, in the reverse movement of the vehicle the obstacle is detected by the back sensor raising the interrupt and making IE register equal to $80 \mathrm{H}$ and the right sensor makes the Interrupt register equal to $40 \mathrm{H}$. Thus the sensors on the vehicle avoid any collision with the obstacle and navigate the vehicle safely around the obstacle and resume the normal tilling operation subsequently.

Operation of Plough: Lowering the plough for the required depth is taken care by stepper motor connected to the upper nibble of Port 3. For a plough depth of about 5 inches, the stepper motor has to be rotated with the pattern of $80 \mathrm{H}, 40 \mathrm{H}$, 
$20 \mathrm{H}$ and $10 \mathrm{H}$ to its windings. This is presented in Figure 14. Once the tilling of a row is completed, the vehicle moves to the next row. The land remains untilled during the lateral movement of the vehicle till the next row is reached. The vehicle would not till the ground even when it is taking a detour due to any obstacle in its path. To ensure that the ground is not tilled during this period, the plough is lifted off the ground during that time. Thereafter, the plough is lifted up by passing the bit patterns $10 \mathrm{H}, 20 \mathrm{H}, 40 \mathrm{H}$ and $80 \mathrm{H}$ in that order to its windings. This is presented in Figure 15. Once the entire tilling operation is completed, the Alarm is turned on by making the Port 3 , bit 2 low. This is presented in Figure 16 . The Alarm may be acknowledged by the User by a separate push button switch (not shown in the waveforms).

Table 2 Signal Description of the Controller

\begin{tabular}{|c|c|c|}
\hline Signal & Input/Output & Description \\
\hline clk & Input & The output is available at the positive edge of the clk. \\
\hline reset & Input & Asynchronous reset pin. System resets when it is high. \\
\hline L & Input & Indicates the length of the field to be tilled. \\
\hline $\mathrm{Br}$ & Input & Indicates the breadth of the field to be tilled. \\
\hline SPACE & Input & Indicates the spacing between one till line to the other. \\
\hline $\mathrm{D}$ & Input & Indicates the depth to be tilled. \\
\hline IE & Input & $\begin{array}{l}\text { Various bits of IE are connected to different sensors as } \\
\text { indicated below: } \\
\text { IE. } 0 \text { is connected to Front Sensor. } \\
\text { IE. } 1 \text { is connected to Left Sensor. } \\
\text { IE. } 6 \text { is connected to Right Sensor. } \\
\text { IE. } 7 \text { is connected to Back Sensor. }\end{array}$ \\
\hline Sen_Len & Input & $\begin{array}{l}\text { Indicates the spacing between the obstacle and the } \\
\text { vehicle. }\end{array}$ \\
\hline P0 & Output & $\begin{array}{l}\text { Connected to wheels through DC Motor for Forward, } \\
\text { Reverse, and Lateral movement. }\end{array}$ \\
\hline P1 & Output & $\begin{array}{l}\text { Connected to wheels through Stepper motor for Lateral } \\
\text { movement (Front Right and Front Left). }\end{array}$ \\
\hline $\mathrm{P} 2$ & Output & $\begin{array}{l}\text { Connected to wheels through Stepper motor for Lateral } \\
\text { movement (Rear Right and Rear Left). }\end{array}$ \\
\hline P3.4-7 & Output & Connected to Plough for depth control. \\
\hline P3.0 & Output & Connected to Turn Table through servo motor. \\
\hline P3.1 & Output & Connected to Lift through servo motor. \\
\hline P3.2 & Output & $\begin{array}{l}\text { Connected to Audio Alarm to indicate the completion of } \\
\text { tilling operation. }\end{array}$ \\
\hline
\end{tabular}




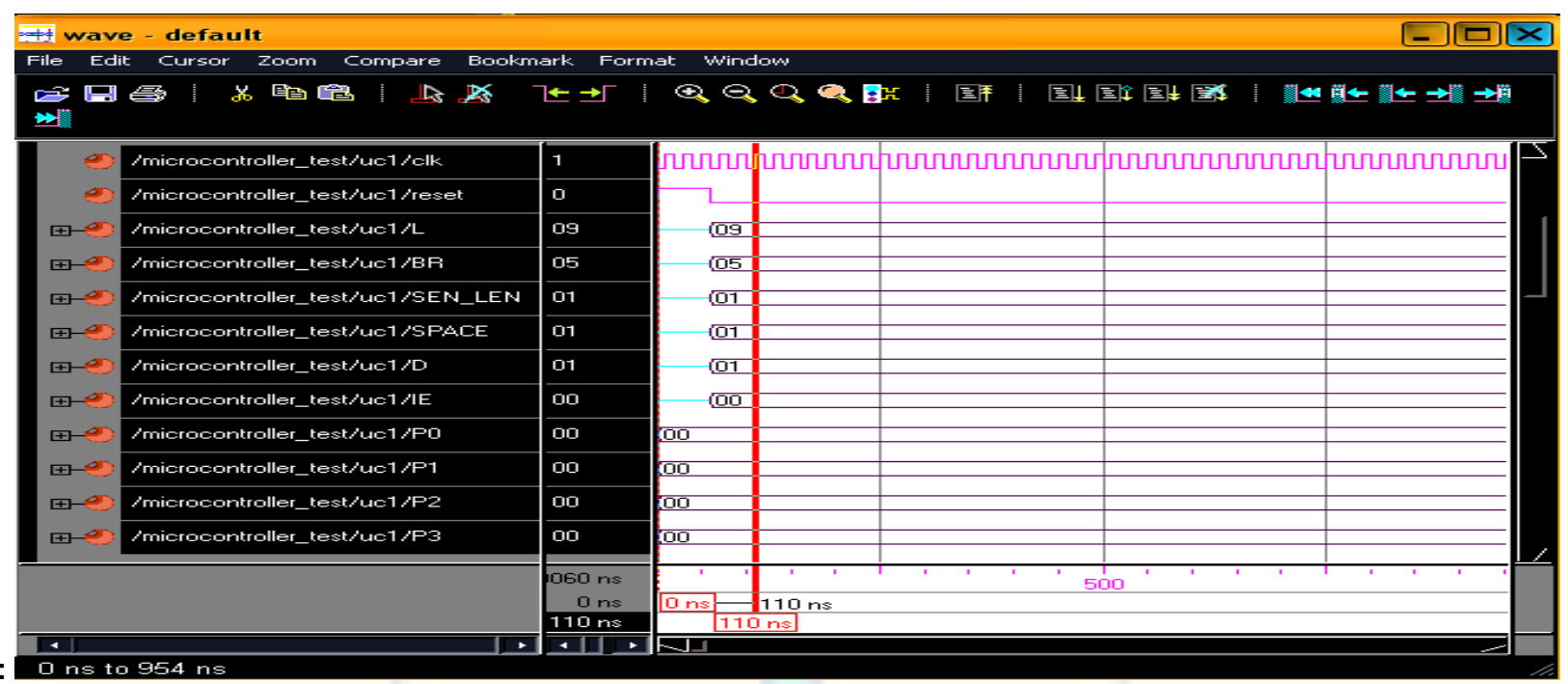

Fig. 7: All Inputs and Outputs of the System

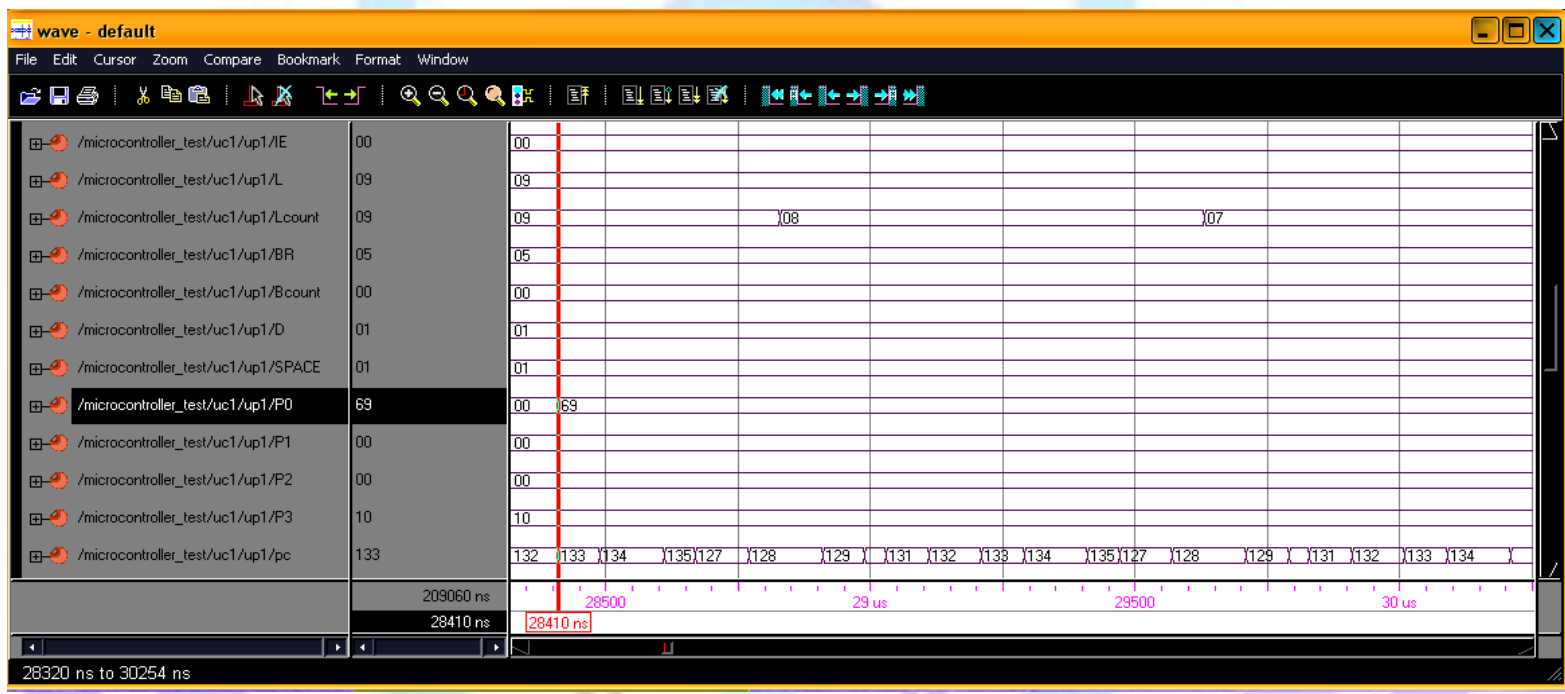

Fig. 8 : Forward Movement of the Robotic Vehicle

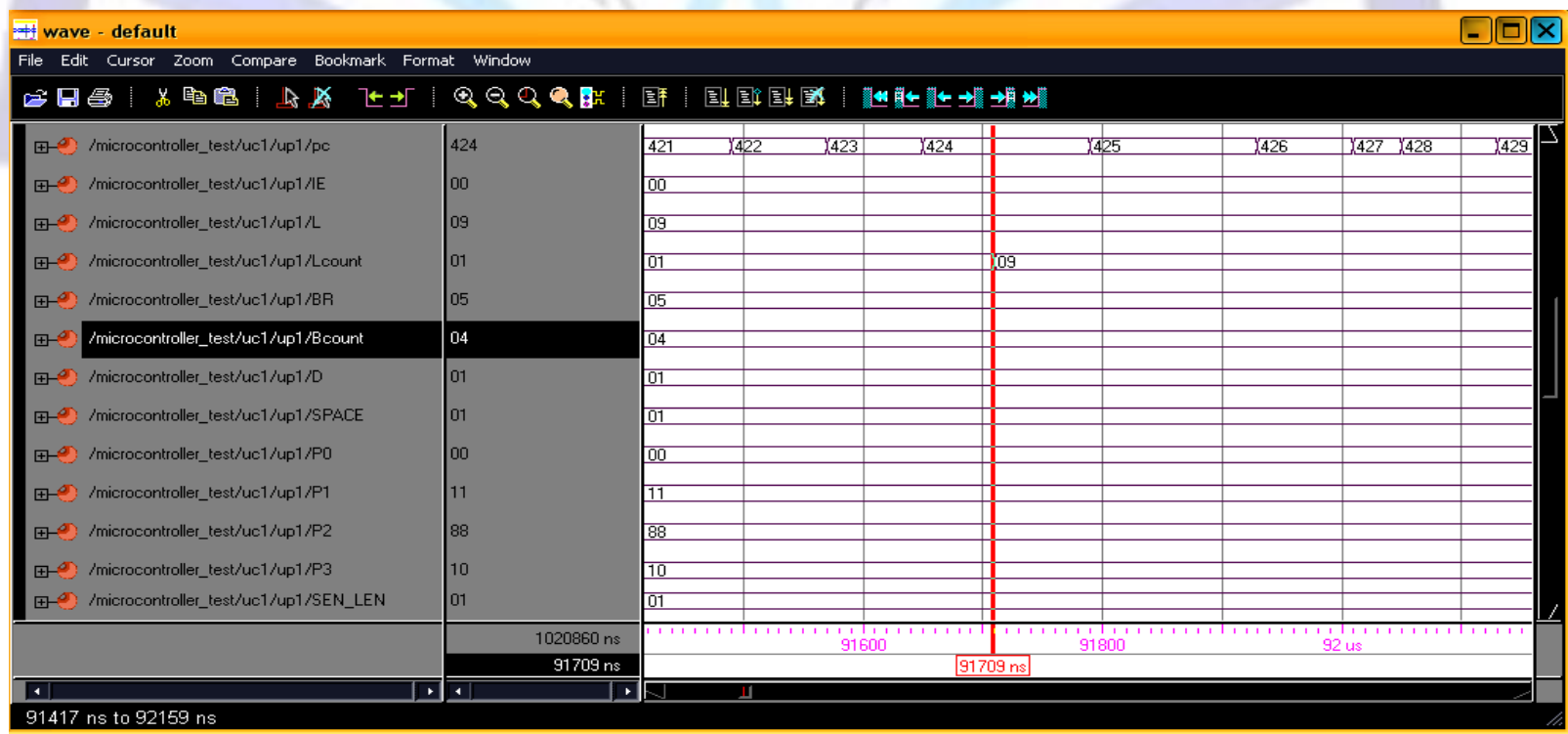

Fig. 9a : Reverse Movement of the Robotic Vehicle: Progress of Tilling Operation - Breadth 


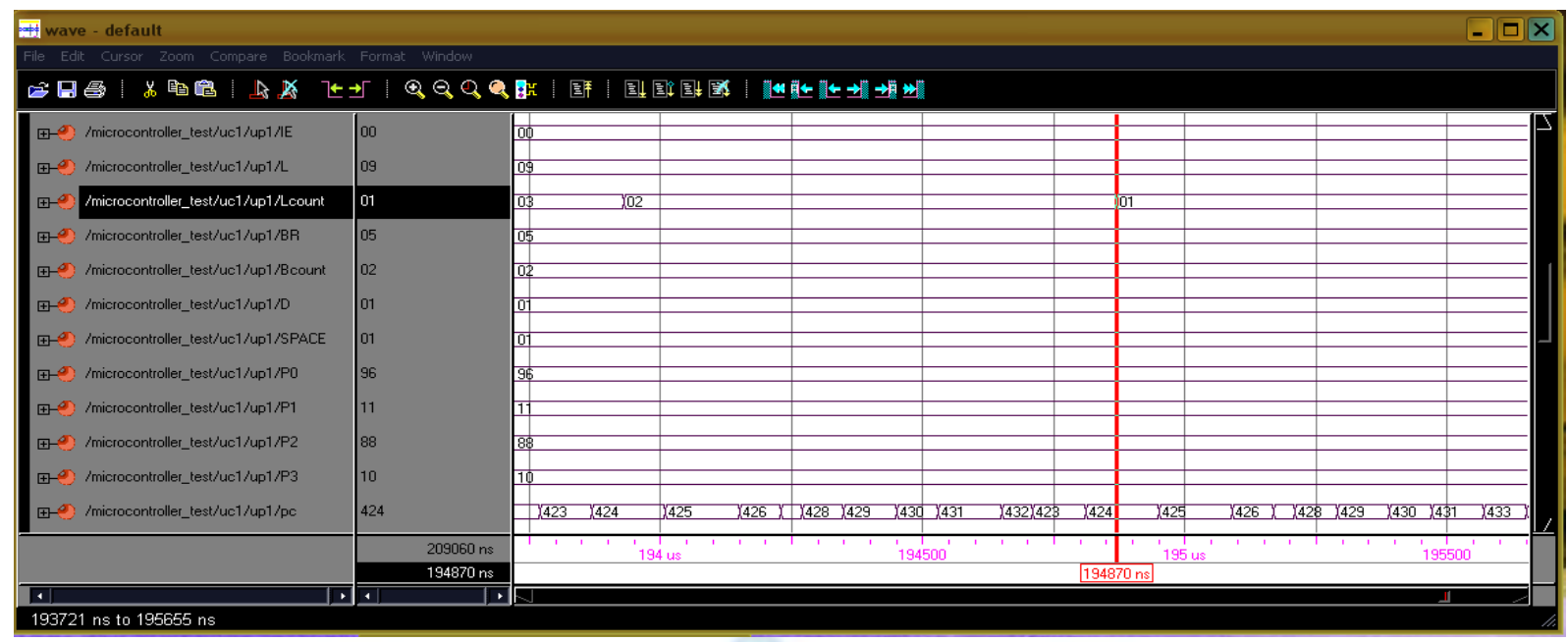

Fig. 9b : Reverse Movement of the Robotic Vehicle: Progress of Tilling Operation - Length

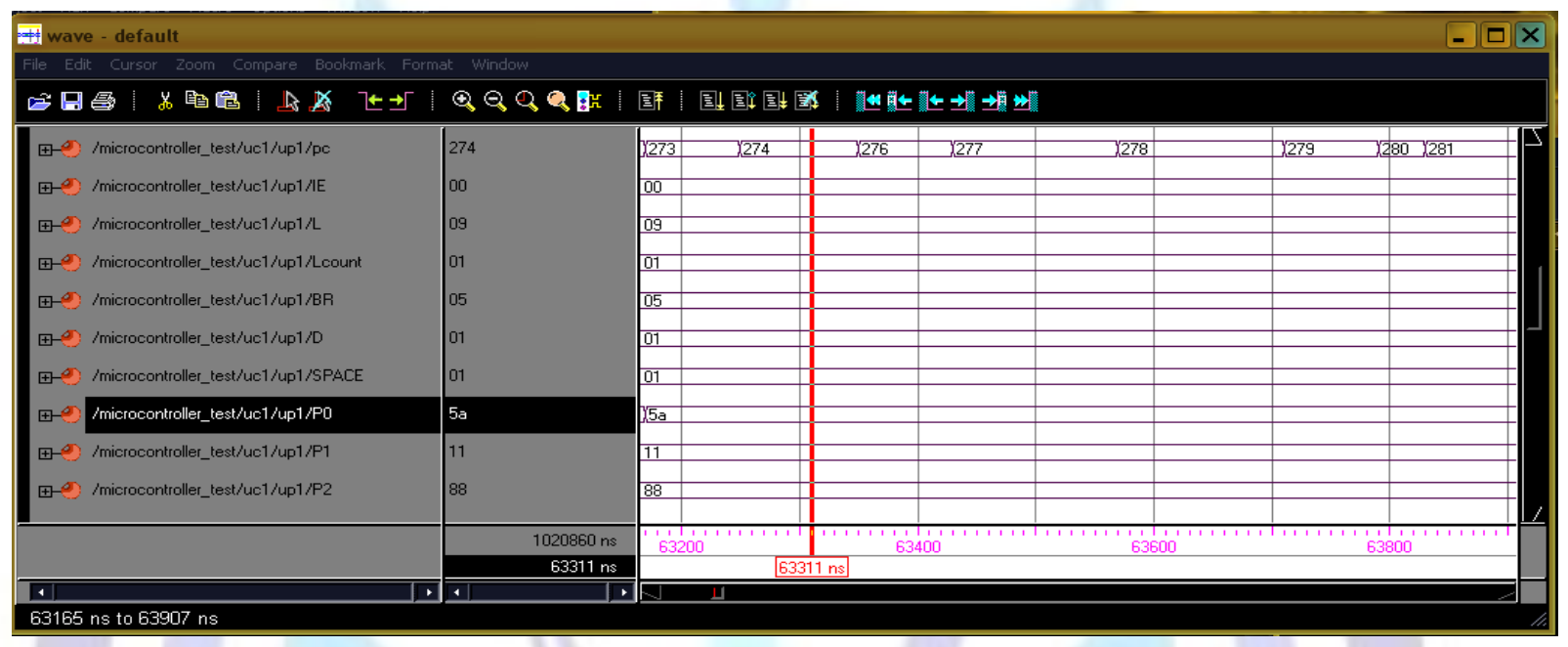

Fig. 10 : Lateral Movement of the Robotic Vehicle

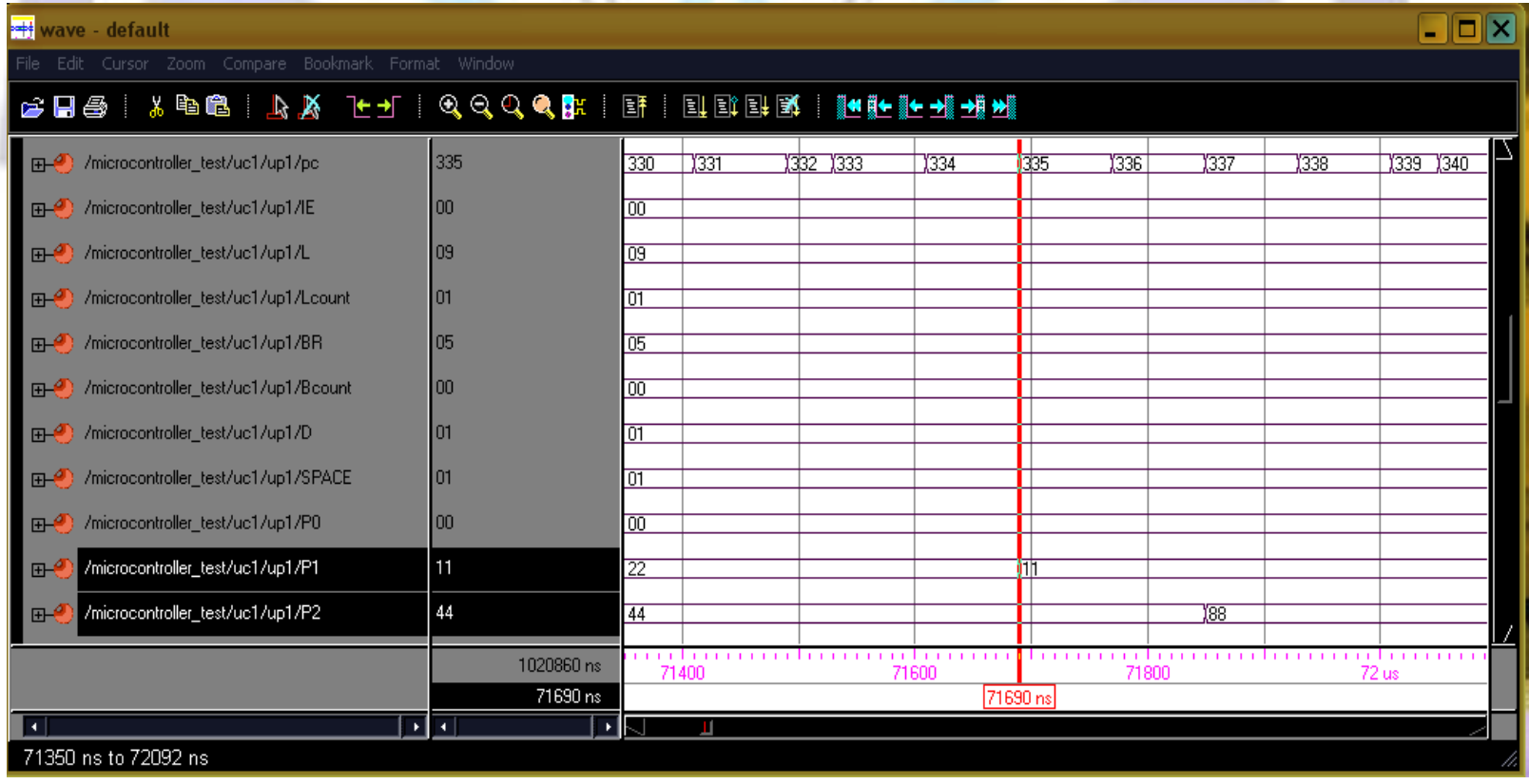

Fig. 11 : Rotation of Wheels by 90 Degrees for Lateral Movement 


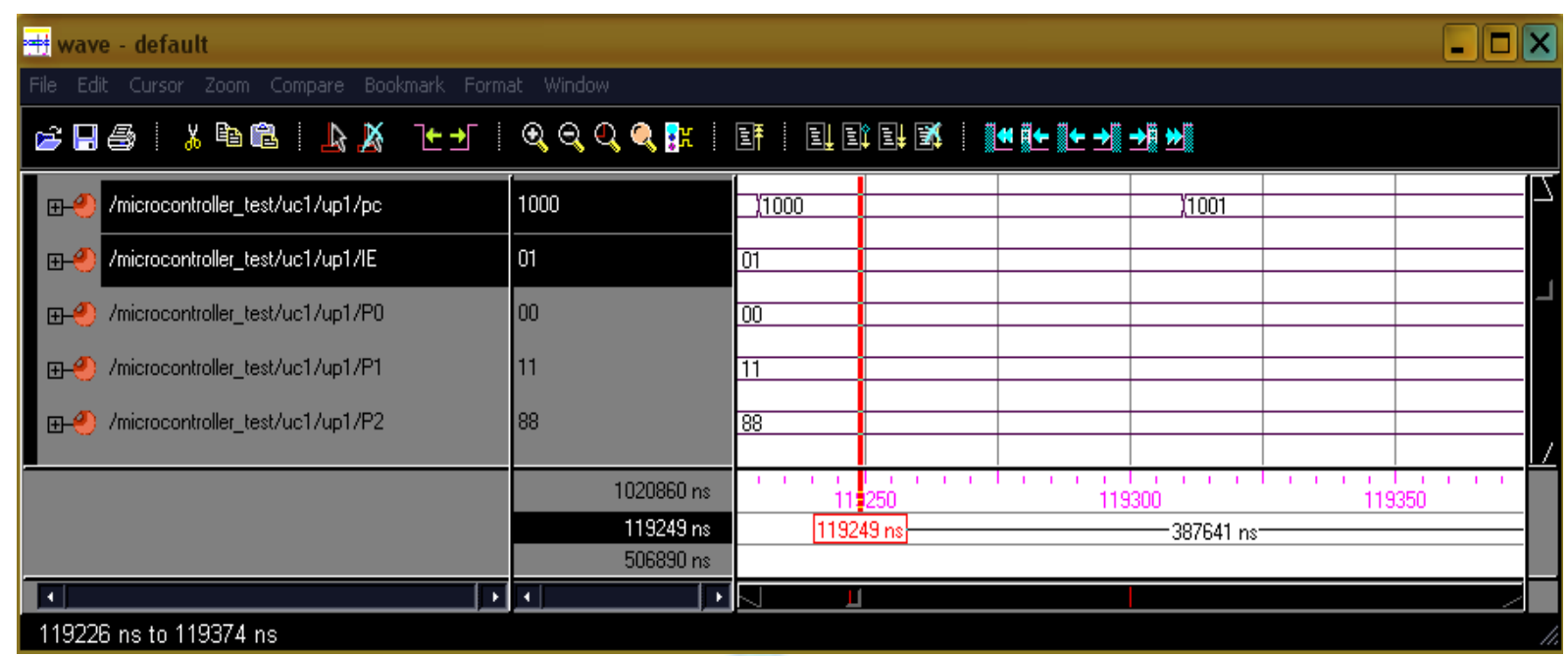

Fig. 12 : Obstacle in Front - Branch to Obstacle Avoidance Service Routine

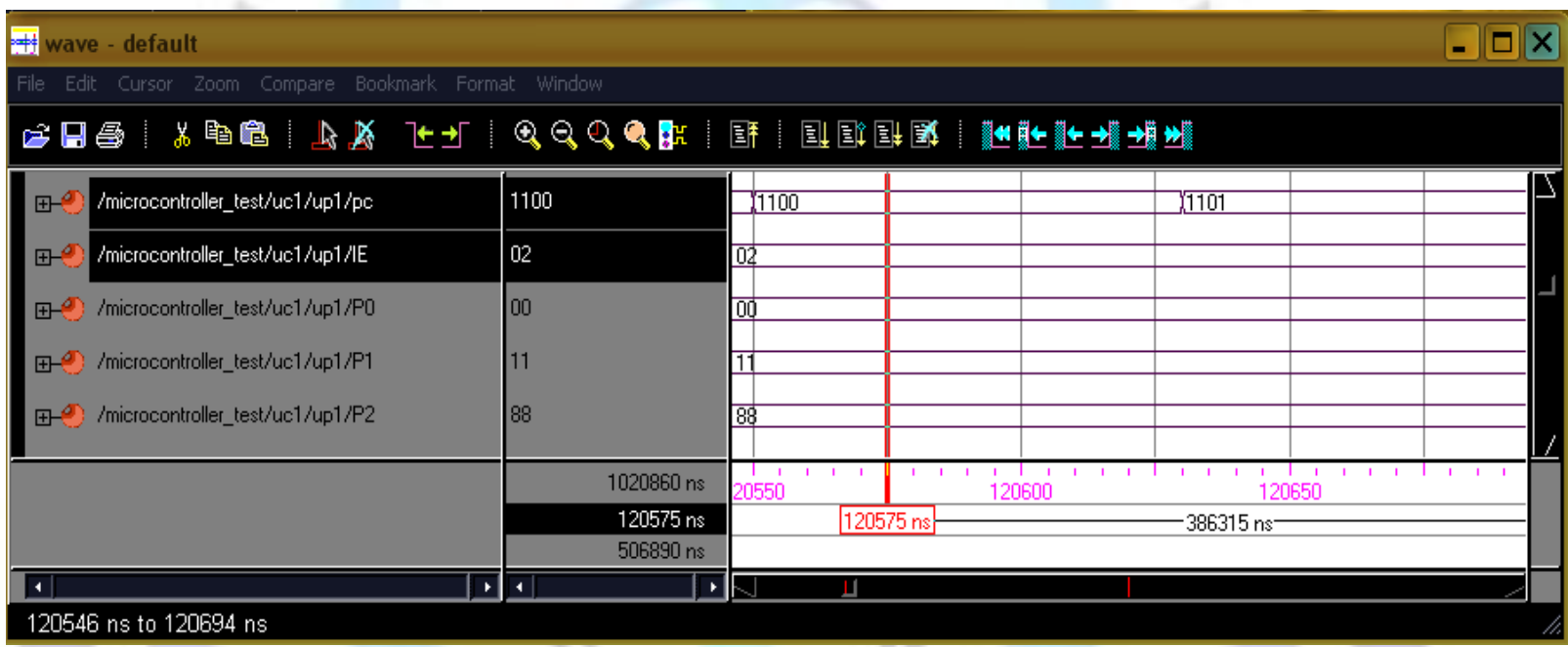

Fig. 13 : Obstacle to the Left - Branch to Obstacle Avoidance Service Routine

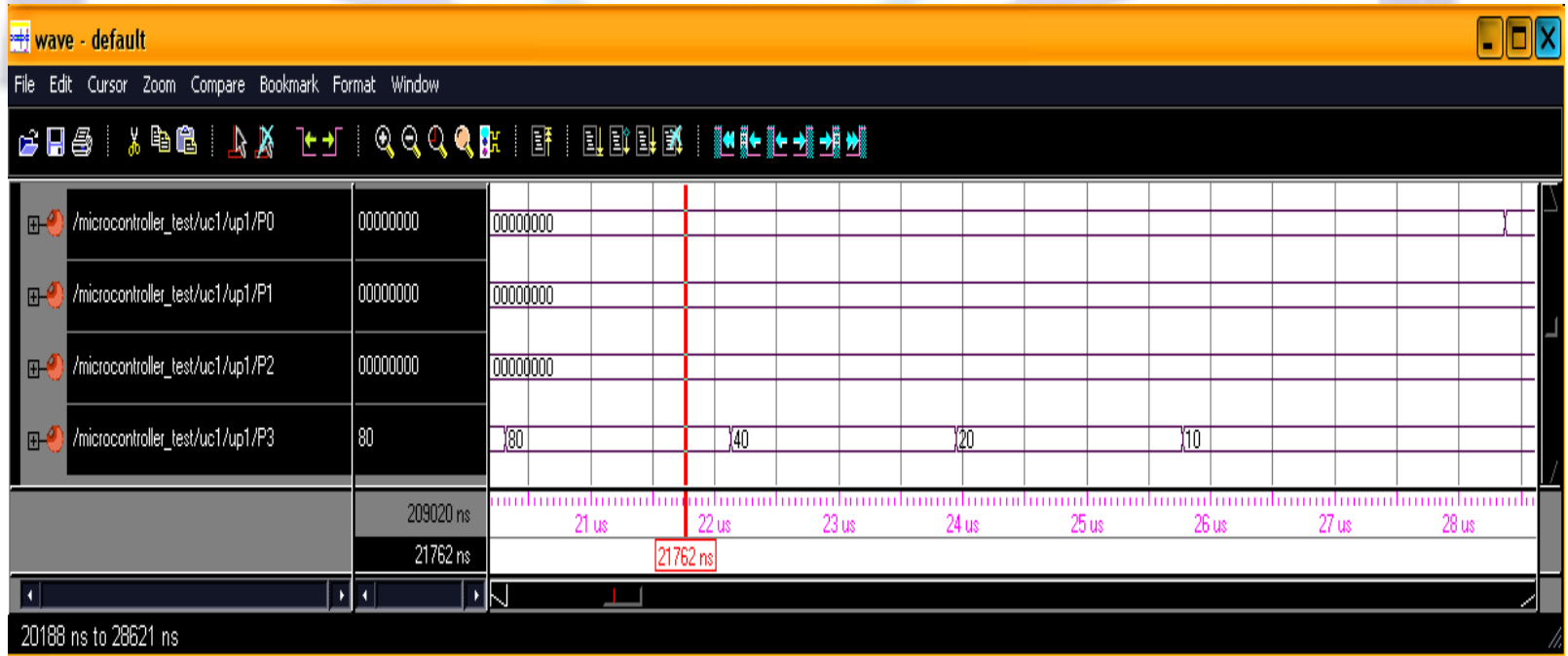

Fig. 14 : Plough Lowered 


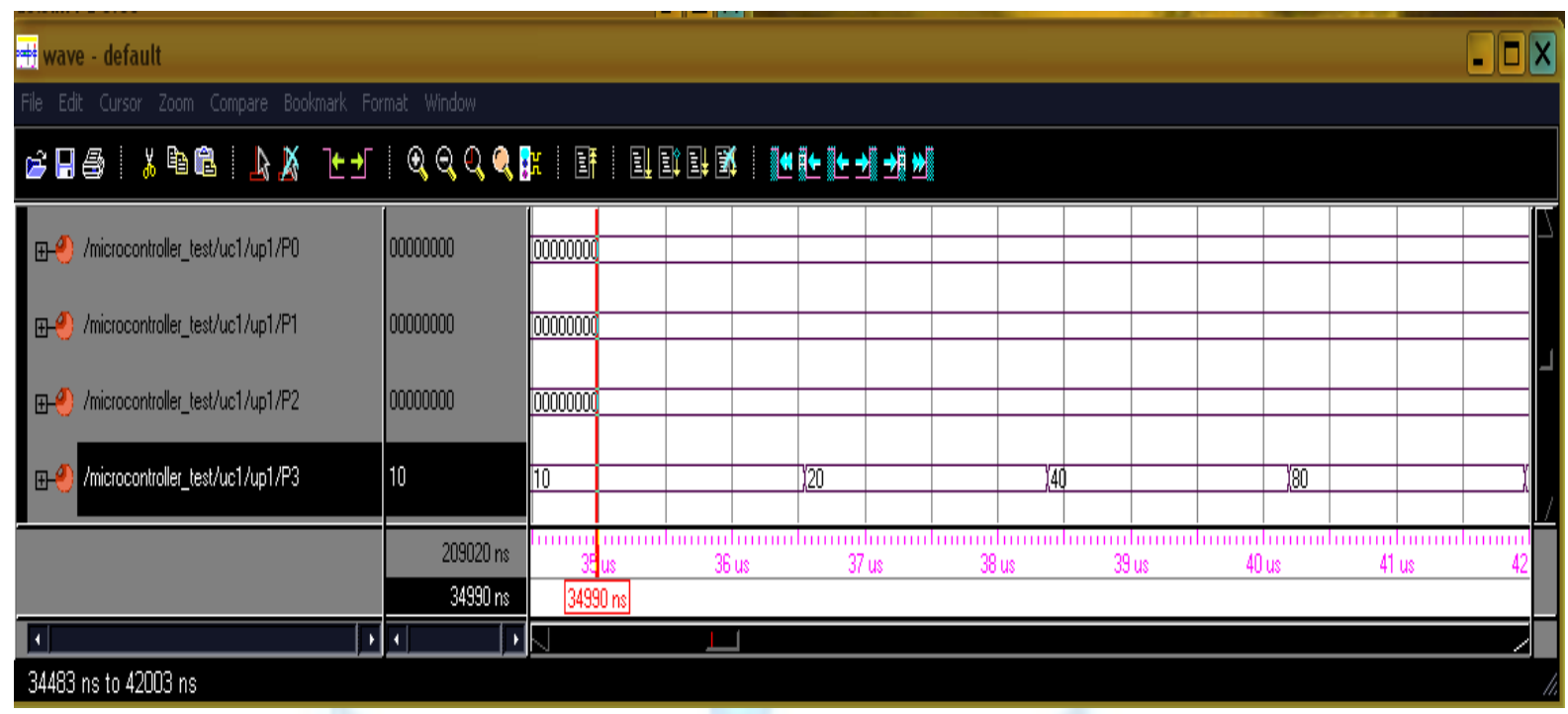

Fig. 15 : Plough Lifted Up from Lowered Position

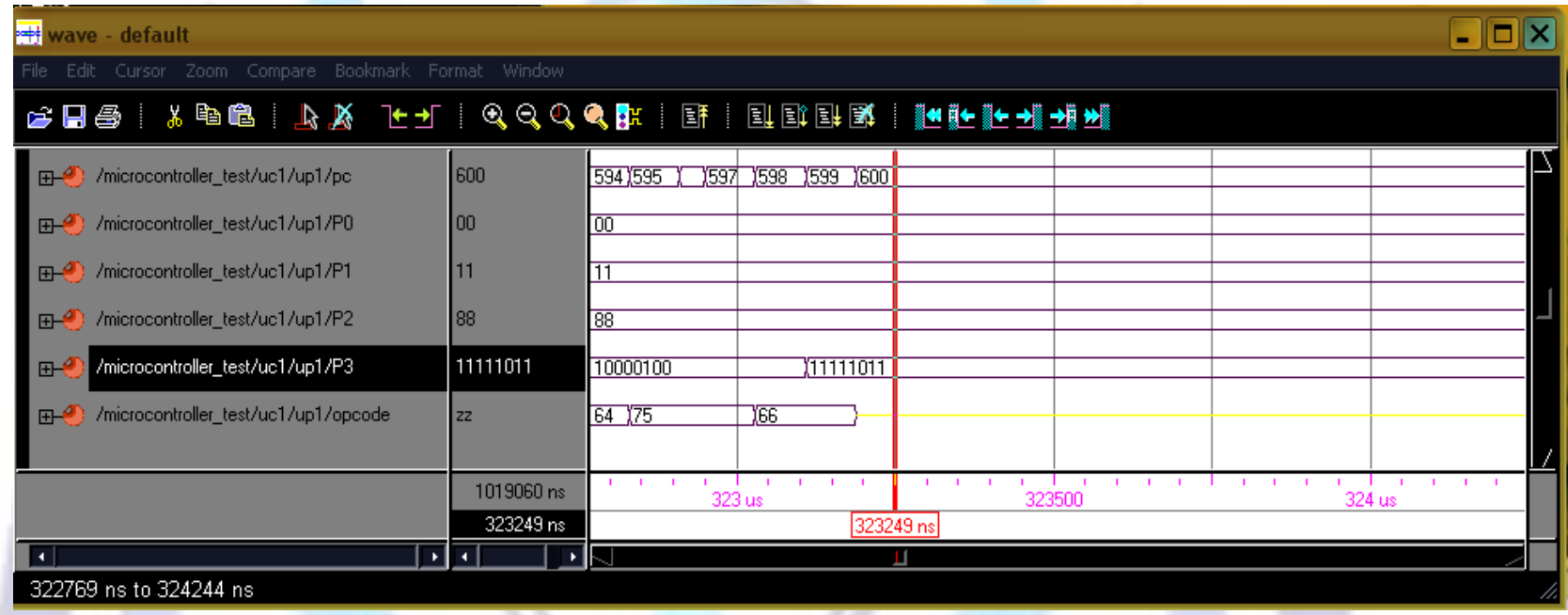

Fig. 16 : Alarm (P3.2) Indicating the End of Operation

\section{CONCLUSION}

A Robot based agricultural implement system has been developed using a customized IP Core. The Robotic System is designed using Verilog with on-chip ports, ROM, and RAM. The instructions have been realized using Algorithmic State Machine charts. The design conforms to RTL coding guidelines and is technology independent. The test bench is also coded using Verilog in order to test the system design. The IP core developed can also be used for all other applications since the IP Core fully emulates a microcontroller such as 8051 . In the present work, the IP core is used to run tilling operation in a field. The field may be tilled to the specified length, breadth and spacing between till lines. The depth of tilling is also programmable. Currently, PID controller is under development in order to achieve precise control of the wheels of the vehicle in a specified direction.

\section{REFERENCES}

[1] Choatpong Kanjanaphachoat, Kuen-Chang Hsieh, Chung-Teh Cheng, and Hwang Mins-Shi, "Combining a differential positioning system and double electric compass to improve multi-path error correction for a high-precision agricultural

robotic vehicle", Maejo International Journal of Science and Technology, 23 May 2011, 5(02), pp. 169-180.

[2] T. Oksanen and A. Visala, "Path Planning Algorithms for Agricultural Machines", Agricultural Engineering International: CIGR Journal, Vol. 9, July, 2007, pp. 1-19.

[3] John Billingsley, John Reid and John Deere, "Agricultural Robotics", Proceedings of the IEEE Robotics \& Automation Magazine, December 2009, pp. 16-19. 


\section{ISSN 22773061}

[4] Xu Jin, Li Yongkang, Zhou Rongyan, and Liu Kai, "Based on embedded intelligent vehicle system", Proceedings of the IEEE International Conference on Computer and Communication Technologies in Agriculture Engineering, 2010, Volume: 2, pp. 49-52.

[5] Freitas, G., Hamner, B., Bergerman, M., and Singh, S. "A practical obstacle detection system for autonomous orchard vehicles", Proceedings of IEEE International Conference on Intelligent Robots and Systems, 2012, pp. $3391-3398$.

[6] Fang, H., Lenain, R., Thuilot, B., and Martinet, P. "Robust Adaptive Control of Automatic Guidance of Farm Vehicles in the Presence of Sliding", Proceedings of the IEEE International Conference on Robotics and Automation (ICRA), 2005, pp. 3102-3107.

[7] Hassan, M. H., and Rosati, M., "Microprocessor guided vehicles for manufacturing applications" , Proceedings of the IEEE, 26th Southeastern Symposium on System Theory, 1994, pp. 601-605.

[8] Han, Y. H., Wang, Y. M., and Kang, F., "Navigation line detection based on support vector machine for automatic agriculture vehicle", Proceedings of the IET International Conference on Automatic Control and Artificial Intelligence, 2012, pp. 1381-385.

[9] Nielsen, K. M., Andersen, P., Pedersen, T. S., Bak, T., and Nielsen, J. D., "Control of an autonomous vehicle for registration of weed and crop in precision agriculture", Proceedings of the IEEE International Conference on Control Applications, 2002,Vol.: 2, pp. 909-914.

[10] Oksanen, T., Linja, M. and Visala, A., "Low-cost positioning system for agricultural vehicles ", Proceedings of the IEEE International conference on Computational Intelligence in Robotics and Automation, 2005, pp. 297-302.

[11] Cariou, C., Lenain, R., Thuilot, B. and Martinet, P. , "Motion planner and lateral-longitudinal controllers for autonomous maneuvers of a farm vehicle in headland", Proceedings of the IEEE International Conference on Intelligent Robots and Systems, 2009, pp. 5782-5787.

[12] Siva Reddy, R. V., Ramachandran, S., and Nagabhushana Raju, K., "IP Core Design for Electrostatic Precipitator Controller System", International Conference on Advances in Information, Communication Technology and VLSI Design (ICAICV), PSG College of Technology, Coimbatore, 2010.

[13] Deepak, B. B. V. L. and Dayal Parhi, "Intelligent adaptive immune-based motion planner of a mobile robot in cluttered environment”, Intelligent Service Robotics, July 2013, Volume 6, pp. 155-162.

[14] Mala, C. S. and Ramachandran, S., "IP Core design of Microcontroller System using Verilog for Robot based Agricultural Implements," in Proceedings of the International Conference on Informatics and Applications 2012, University Sultan Zainal Abidin, Kuala Terengganu, Malaysia, June 3-5, 2012, pp. 213-227.

[15] Mala, C. S. and Ramachandran, S., "Realization of IP Core for Robot Controlled Trenching System," The Society of Digital Information and Wireless Communications, International Journal of New Computer Architectures and their Applications, 2(4), Nov. 2012,

\section{Author' biography}

C. S. Mala is presently working as an Associate Professor in the department of Electronics and Communication in BM Sreenivasiah Institute of Technology, Bangalore. She is pursuing her PhD in JNTUH, Hyderabad.

S. Ramachandran obtained his M.Tech. and Ph. D. degrees from the Indian Institute of Technology, Kanpur and Madras respectively. He has wide academic as well as industrial experience of over 35 years, having worked as Professor in various engineering colleges as well as design engineer in industries in India and USA, designing systems and teaching/guiding students. His research interests include developing algorithms, architectures and implementations on FPGAs/ASICs for Video Processing, DSP applications, reconfigurable computing, open loop control systems, etc. He is the recipient of the Best Design Award at VLSI Design 2000, International Conference held at Calcutta, India and the Best Paper Award of the Session at WMSCI 2006, Orlando, Florida, USA. He has completed a video course on Digital VLSI System Design at the Indian Institute of Technology Madras, India for broadcast on TV by National Programme on Technology on Enhanced Learning (NPTEL) and is being broadcast in You Tube as well. He has also written a book on Digital VLSI Systems Design, published by Springer Verlag, Netherlands (www.springer.com). 